\title{
A EDUCAÇÃO PORTUGUESA ATRAVÉS DO MONÓLOGO DE EÇA DE QUEIRÓS
}

\author{
Marcio Jean Fialho de Sousa ${ }^{1}$
}

RESUMO: Este trabalho se propõe a observar como Eça de Queirós registra seu contributo ao discursar sobre o novo estilo literário e, em seguida disponibiliza n'As farpas as suas críticas à educação portuguesa.

PALAVRAS-CHAVE: Educação; Portugal; Eça de Queirós; debate; proposta pedagógica.

ABSTRACT: The present paper intends to analyze how Eça de Queirós registers his contribution when he discourses about the new literary style and, right away, he shows in As farpas his criticism of Portuguese education.

KEYWORDS: Education; Portugal; Eça de Queirós; debate; pedagogical proposal.

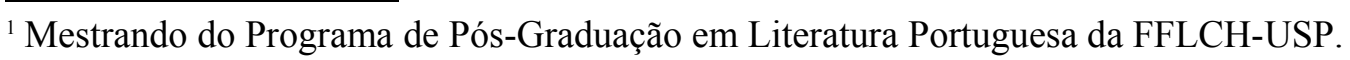


A discussão acerca das questões educacionais, desde o século XVIII, se tornou parte de uma das diversas tradições portuguesas, de modo que várias propostas de reforma educacional foram surgindo gradualmente no decorrer das décadas, tais como as apresentadas por António Ribeiro Sanches, Luís António Verney, no século XVIII e Luís Mousinho de Albuquerque, António Feliciano de Castilho, Almeida Garrett, Alexandre Herculano entre outros, na primeira metade do século XIX. Porém, por mais que a educação em Portugal tivesse se tornado um tema quase que obrigatório nos círculos intelectuais era, ainda, uma questão secundária nos meios políticos.

Essa indiferença política quanto à educação foi o que impulsionou os escritores a debaterem acerca desse problema considerado fundamental para o crescimento social e econômico português, bandeira essa que foi, também, sustentada pela Geração de 70 .

Segundo António Machado Pires ${ }^{2}$, a estrutura do sistema educacional português faziase pela "leitura, pelo espetáculo, pelo exemplo, era amolecedora de caracteres, falseadora dos ideais, era sintoma e causa de decadência social e moral" (PIRES, 1992, p. 154), ou seja, o que se praticava nessa educação, muitas vezes, era a perpetuação de conceitos e atitudes morais pertencentes à burguesia, dessa forma, os valores sociais deveriam ser copiados, de modo que não houvesse reflexão.

Ao abordar assuntos referentes à questão educacional portuguesa, Eça de Queirós, ao proferir sua conferência no Casino, em 1871, teve como objetivo discursar a respeito do que chamou de "literatura de sentimento", dizendo que essa cederia o lugar à "anatomia do caracter", levando-nos a compreender seu ponto de vista acerca da educação vigente em sua época, ou seja, a educação que se preocupava com a imitação e a leitura pura e simplesmente, deveria ser banida, dando espaço a uma educação reflexiva nos pormenores, de modo a transformar um todo social. Para combater o que chamou de literatura de sentimento seria necessário um novo jeito de pensar, uma nova maneira de ver a realidade, que pressupunha uma nova educação a ser praticada.

Para António Patrício, no In Memoriam de Eça de Queirós (1922), o cronista analisa a educação portuguesa tendo como parâmetro a educação estrangeira, em especial a francesa, fazendo com que uma visão superior da educação fosse valorizada em detrimento da portuguesa.

Dessa forma, a partir de uma perspectiva cronológica é possível observar que nas primeiras publicações há uma grande preocupação com as questões estruturais da educação, apresentadas em Uma Campanha Alegre: Das Farpas (1871), passando pelas questões

\footnotetext{
${ }^{2}$ Cf.: PIRES, António Machado. A idéia de decadência na Geração de 70. $2^{\circ}$ ed. Lisboa: Vega, 1992.
} 
ideológicas que tenta demonstrar as possíveis causas da degeneração e estagnação da cultura portuguesa, presentes, de modo particular, em Notas Contemporâneas (1880-1881).

Carlos Reis, em Eça de Queirós e o discurso da história ${ }^{3}$, afirma que é comum, nas obras de Eça, aparecer a preocupação com os problemas educacionais, para isso destaca os inúmeros romances que abordam os programas pedagógicos, por meio dos quais se teriam formado as diferentes personagens.

Desse modo, Eça de Queirós, estabelece relações entre a personalidade adulta e o modelo de educação que recebeu durante a formação de sua personalidade. Esse modelo é retratado pelo romancista por intermédio da reconstituições das personalidades sociais que foram retratadas em suas obras, assim como o conhecido padre Amaro, em $O$ crime do padre Amaro, representante do clero português, Luísa, personagem da famosa obra $O$ primo Basílio, representante da mulher burguesa em Portugal, Teodorico Raposo, d'A Relíquia, entre outros.

Porém, o que se pretende demonstrar neste artigo não é a importância que Eça de Queirós dá à problemática educacional em seus romances ficcionais e sim como apresenta essa mesma problemática em seus textos críticos, nos quais se posiciona de modo claro e objetivo.

Com efeito, a produção cronística de Eça de Queirós que apresenta temas relacionados à discussão educacional foi pensada e viabilizada, inicialmente, em parceria com Ramalho Ortigão, no ano de 1871, quando publicaram As Farpas, obra que dá continuidade a uma problemática crítico-revolucionária iniciada ano anterior com a publicação de $O$ Mistério da Estrada de Sintra, que segundo Luís de Albuquerque $(1978)^{4}$, teve como objetivo apresentar o ambiente cultural português da época ${ }^{5}$. O próprio Eça de Queirós, no prefácio, disse que tinha como objetivo para essa obra "acordar tudo aquilo que a berros, num romance tremendo, buzinando à Baixa das alturas do Diário de Notícias," (QUEIRÓS \& ORTIGÃO, 1992, p. 30) em seguida afirma parecer ter conseguido atingir suas metas, se não pelo interesse, pela curiosidade.

Palavras essas que o autor retoma no texto de abertura do primeiro folheto d'As Farpas:

Leitor de bom senso - que abres curiosamente a primeira página deste livrinho, sabe, leitor - celibatário ou casado, proprietário ou produtor, conservador ou revolucionário, velho patuleia ou legitimista hostil - que foi

\footnotetext{
${ }^{3}$ REIS, Carlos. Queirosiana: estudos sobre Eça de Queirós e a sua geração. Números 7/8. Dezembro, $1994 .$, p. 46

${ }^{4}$ Cf.: ALBUQUERQUE, Luís de. Estudos de História. Vol. VI (Notas para a História do ensino em Portugal), Coimbra, Por ordem da Universidade, 1978.

${ }^{5}$ Cf. REIS, Carlos. As Conferências do Casino. Lisboa, Publicações Alfa, s.d.
} 
para ti, que ele foi escrito - se tens bom senso! E a idéia de te dar assim todos os meses, enquanto quiseres, cem páginas irônicas, alegres, mordentes, justas, nasceu no dia em que pudemos descobrir através da penumbra confusa dos factos, alguns contornos do perfil do nosso tempo. (QUEIRÓS \& ORTIGÃO, s/d, p. )

As Farpas, pelas palavras de Carlos Reis, possui um tom crítico, sarcástico e, às vezes, cômico acompanhada por um propósito de índole pedagógico, ${ }^{6}$ que nos possibilita afirmar, com segurança, que buscou estabelecer uma reforma social dos costumes e mentalidade que rondava a política, o ensino, a literatura e todos os campos da sociedade portuguesa, não deixando de assinalar a ironia que é utilizada pelo escritor:

Nós não queremos também que num país como este, ignorante, desorganizado, se lance através das ambições e das cóleras o grito de revolta! Queremos a revolução preparada na região das idéias e da ciência; espalhada pela influência pacífica duma opinião esclarecida... (QUEIRÓS, 2000, p. 703)

Com As Farpas, Eça de Queirós introduz suas críticas diretas ao sistema educacional de modo incisivo e categórico, postura essa que nas suas crônicas posteriores a essa publicação aparece com uma leve mudança de tom crítico, assim como de conceitos que n'As Farpas foram apresentados de modo imutável. ${ }^{7}$

Em março de 1872, Eça de Queirós afirmou ser do governo municipal a responsabilidade pela educação pública, ${ }^{8}$ porém, esse governo não demonstrava preocupação alguma com os assuntos de formação intelectual, tanto que não contribuía financeiramente com tal questão de suma importância, deixando-a abandonada ao ocaso. Por isso, Eça afirma, ainda, que o valor de uma geração dependeria da educação que recebesse das mães, já que o acesso à instrução formal era quase que inviável, ${ }^{9}$ ou seja, já que o governo não se responsabilizava com a educação formal, as mães é quem deveriam assumir com empenho essa responsabilidade. Afirmação essa que não aparece como algo inédito em Portugal, já que Almeida Garrett também havia abordado essa proposta na obra Da Educação, em 1829.

Nessa obra, Garrett dedica o primeiro capítulo inteiramente à educação doméstica acreditando que a verdadeira educação inicia-se em casa. Eça de Queirós, por sua vez, vê a educação doméstica como uma alternativa eficaz, já que a educação formal não estava

\footnotetext{
${ }^{6}$ REIS, Carlos. As Conferências do Casino. Lisboa: Alfa, 1990., p. 30.

${ }^{7}$ Cf.: REIS, Carlos. O essencial sobre Eça de Queirós. S.1.: Imprensa Nacional-Casa da Moeda, s.d., p. 05.

${ }^{8}$ QUEIRÓS, Eça de. Uma campanha alegre: das farpas. In Obras Completas. RJ: Editora Nova Aguilar S.A., 2000., p. 842.

${ }^{9}$ QUEIRÓS, Eça de. Op. Cit., p. 848.
} 
preparada para atender a uma grande demanda, além disso, era comum esse tipo de educação em Portugal, principalmente em se tratando da população menos favorecida financeiramente.

Também Antero de Quental, num texto dedicado à Educação das Mulheres, ${ }^{10}$ afirma que toda a formação humana, o caráter de cada ser dependeria do que teria sido ensinado por suas mães, ou seja, a educação feminina acaba por ser vista como fundamental, com outras palavras, diz o autor:

Bebemos, com efeito, nos seios da mãe, nos olhos da amante, nos braços da esposa todas as virtudes ou todos os vícios, com que depois surgimos no mundo: sendo a mulher o mistério guia, e mestra da nossa educação moral, em todas as fases da nossa vida, claro é que, o que fomos no bem ou no mal, a ela o devemos (QUENTAL, 1982, p. 112).

Por esse motivo apresentado, Antero continua dizendo que a educação:

(...) não deve começar nem pelo clero, nem pelo povo, nem pelas escolas, nem pelos mestres, mas pelos mestres naturais, - pelas mulheres, com as mulheres, e só pelas mulheres; pelas mães, pelas filhas, pelas amantes, pelas esposas... (Idem, ibidem)

Por outro lado, a mulher do século XIX não possuía sua própria independência, vivia em função dos afazeres domésticos; quando solteiras viviam sonhando com o futuro marido, e quando casada devia se dedicar a cuidar do marido e dos filhos, de modo que a educação formal, na prática, não se fazia necessária.

Se assim era o que ocorria na vida das mulheres do Portugal oitocentista, então logo se compreende o porquê as autoridades governamentais não se interessavam com as questões educacionais e, principalmente, com a educação das mulheres portuguesas, pois se a sina dessas mulheres era viver para a sua família, de que serviria estudar?

O que não se tinha em mente, na cultura da época, era que também essas mulheres poderiam corroborar com o crescimento da nação. Essa consciência, porém, fez parte dos escritos de Verney, na intitulada obra O Verdadeiro Método de Estudar, na qual apresentou uma proposta de educação para o século XVIII.

Outro motivo apresentado por Eça de Queirós em relação à educação feminina era a preguiça, que segundo afirmou era um dos grandes males que atingia a sociedade portuguesa contemporânea, de modo particular as mulheres que já tinham seu futuro educacional comprometido com a futura vida matrimonial.

Consequentemente, a educação feminina não tinha muita relevância prática na vida das mulheres, pois se a sociedade as havia colocado na posição de donas-de-casa o máximo

\footnotetext{
${ }^{10}$ Publicado e apresentado por Joel Serrão em Prosas Sócio-Políticas.
} 
que os estudos poderiam ser úteis seria na educação dos filhos, o que para a maioria dos intelectuais, incluindo Eça de Queirós, seria uma das saídas para o início do crescimento cultural da nação portuguesa.

Em contrapartida a essa proposta de educação doméstica, o que se via era que a "cultura da ignorância” estava enraizada de tal forma na sociedade que, Eça de Queirós, na crônica publicada em junho de 1871, n'As Farpas, dissera que:

O homem à maneira que perde a virilidade de caráter, perde também a individualidade de pensamento. Depois não tendo de formar o caráter, porque ele lhe é inútil e teria a todo o momento de o vergar; não tendo de formar uma opinião, porque lhe seria incômoda e teria a todo o momento de a calar - costuma-se a viver sem caráter e sem opinião. Deixa de freqüentar as idéias, perde o amor da retidão. Cai na ignorância e na vileza (QUEIRÓS, 2000, p. 676).

Portanto, o processo de decadência em Portugal torna-se tão pitoresco entre a população, que chega a incorporar no indivíduo a idéia de que a formação do caráter, a educação, tornara-se algo inútil, incômoda, sendo assim, o melhor seria viver na ignorância, pois pelo menos essa não exigiria esforço.

Os professores de instrução primária são apresentados por Eça de Queirós como sendo uma figura "desgraçada"11. Vale salientar que, além de receber um salário medíocre, o professor primário não possuía carreira, o que lhe proporcionava falta de estímulo, abandonando-se à rotina, de modo que o professor havia se transformado, segundo afirma Eça, em um empregado de eleições. ${ }^{12}$

Com toda essa falta de incentivo ao profissional da educação, não seria possível esperar um bom resultado proveniente da educação formal no país. ${ }^{13}$ Algo que seria no mínimo preocupante para qualquer sociedade que tivesse o ensejo de se engajar no mundo considerado moderno aos olhos dos intelectuais, como era o caso português.

Dessa forma, os intelectuais foram percebendo a discrepância entre a cultura portuguesa com a estabelecida na Europa moderna, acaram produzindo a chamada "mentalidade decadentista", ${ }_{14}$ tendo seu marco na década de 1870.

Esse sentimento pessimista e decadentista impulsionou os intelectuais a se esforçarem para obterem uma atualização frente à cultura européia, buscando muitas vezes reproduzirem

\footnotetext{
${ }^{11}$ QUEIRÓS, Eça de. Op. cit., p. 845.

${ }^{12}$ Ibid. Ibidem., p. 664.

${ }^{13}$ Ibid. Ibidem, p. 846.

${ }^{14}$ Cf. SERRÃO, Joel. Do sebastianismo ao socialismo. Lisboa: Horizonte, 1983.
} 
costumes e idéias dos países considerados modernos, como por exemplo, a França, fonte de inspiração oitocentista em Portugal.

Essa tendência à reprodução de costumes e idéias de outros países em Portugal tornouse uma prática tão pitoresca na segunda metade do século XIX, que, Eça de Queirós tentou reproduzir em alguns de seus textos, o quanto a cultura portuguesa estava se tornando rendida ao modelo educacional francês, como os presentes em Notas Contemporâneas.

Para Eça, as tentativas de renovação da educação em toda a Europa, apresentadas por diversos intelectuais e as poucas que, de fato, foram colocadas em prática, tinham sido de grande valia, porém não tinham, ainda, conseguido atingir todos os habitantes europeus.

Em contrapartida, o que se verifica também em outros textos produzidos nos anos finais da década de 1880 é uma mudança de paradigma, o que notadamente pode ser verificado no artigo "O Francesismo", publicação póstuma 1921. ${ }^{15}$ Nesse texto, Eça inicia dizendo: "Há já longos anos que eu lancei esta fórmula: - Portugal é um país traduzido do francês em vernáculo" (QUEIRÓS, 2000, p. 2107). Afirma, portanto que também fez parte do grupo que valorizava a França, colocando-a num status de um país superior culturalmente, desejando que Portugal, sendo inferior, assumisse a posição de inferioridade, e por ser incapaz de se desenvolver de modo independente só lhe resta se inspirar nos modos e costumes franceses, a ponto de ser uma réplica, uma tradução da França.

Porém, mais adiante no mesmo parágrafo, Eça chega à conclusão de que Portugal não passa de uma cópia mal feita dos costumes franceses. Dessa forma, avalia essa tentativa de reproduzir costumes de outros países como uma privação dos desejos e prazeres nacionais, uma descaracterização do nacionalismo e uma supervalorização do estrangeirismo.

Portugal, segundo Eça, na tentativa de adquirir uma civilização que se equiparasse à França, considerada superior, acabou perdendo sua identidade nacional, assumindo para si uma identidade que não lhe pertencia: a francesa.

Nessa mesma perspectiva, intitulado "Brasil e Portugal”, Eça também demonstra a influência francesa na educação portuguesa ao se direcionar a Pinheiro Chagas dizendo:

Por isso você...olhou em redor. E que viu? Um espetáculo triste: uma mocidade... odiando o solo em que nascera, a língua que falava, a educação que recebera, amuada dentro desse ódio estério... tão alheio à Pátria e ao seu gênio como se tivesse sido importada de França, em caixotes, pelo paquete do Havre! Isto era suficiente para indignar um coração... (QUEIRÓS, 2000, p. 1646)

\footnotetext{
${ }^{15}$ Encontrado entre os papéis do escritor, publicado postumamente em 1912 na coletânea intitulada Últimas Páginas, e que segundo Guerra da Cal, em nota de rodapé das obras completas de Eça de Queirós, dataria de 1887 que o considera de sumo interesse bio-literário. (QUEIRÓS, Eça. "O Francesismo.” In. Obras Completas. Vol. III. Org. Beatriz Berrini. Rio de Janeiro: Editora Nova Aguilar, 2000., p. 2107.)
} 
Portanto, ao mesmo tempo em que Eça de Queirós denuncia as práticas pedagógicas pouco originais, baseadas exclusivamente nos métodos franceses, demonstra como a educação na Europa, em geral, também se distancia do ideal. Por um lado, Portugal se perde na busca por uma identidade nacional na medida em que copia modelos estrangeiros, por outro, os países europeus que possuíam um sistema educacional evoluído precisava encontrar novas formas de democratizar ainda mais a educação formal.

Dessa forma, o que Portugal precisava, para Eça de Queirós, era criar novos métodos educacionais que valorizassem a nação, privilegiando o vernáculo e a cultura que lhe era inerente, assim o combate à decadência nacional portuguesa poderia começar a ser pensada.

\section{Referências Bibliográficas}

ALBUQUERQUE, Luís de. Estudos de História. Vol. VI (Notas para a História do ensino em Portugal), Coimbra, Por ordem da Universidade, 1978.

PIRES, António Machado. A idéia de decadência na Geração de 70. 2. Ed. Lisboa: Vega, 1992.

QUEIRÓS, Eça de. ORTIGÃO, Ramalho. As Farpas. Vol. I. Rio de Janeiro: Dois Mundos Editora, s.d.

QUEIRÓS, Eça de. ORTIGÃO, Ramalho. Prefácio a O Mistério da Estrada de Sintra. Porto: Lello, 1967.

QUEIRÓS, Eça de. “Uma campanha alegre: das farpas”. In. Obras Completas. Rio de Janeiro: Editora Nova Aguilar S. A., 2000.

QUENTAL, Antero de. Prosas Sócio-Politicas. Publicada por Joel Serrão. Imprensa nacional - Casa da Moeda, 1982.

REIS, Carlos. O essencial sobre Eça de Queirós. S.1.: Imprensa Nacional-Casa da Moeda, s.d. . As Conferências do Casino. Lisboa: Alfa, 1990.

SERRÃO, Joel. Do sebastianismo ao socialismo. Lisboa: Horizonte, 1983. 